See discussions, stats, and author profiles for this publication at: https://www.researchgate.net/publication/327660345

\title{
Ductility and Plasticity of Nanostructured Metals: Differences and Issues
}

Article · September 2018

DOI: 10.1016/.jmtnano.2018.09.004

\section{CITATION}

1

2 authors:

(6) Yuntian T. Zhu

North Carolina State University

497 PUBLICATIONS 23,023 CITATIONS

SEE PROFILE

Some of the authors of this publication are also working on these related projects:

Project $316 \mathrm{~L}$ austenitic stainless steel View project

Structural evolution induced by severe plastic deformation View project
Xiaolei Wu

Chinese Academy of Sciences

164 PUBLICATIONS 4,175 CITATIONS

SEE PROFILE 


\title{
Ductility and plasticity of nanostructured metals: differences and issues
}

\author{
Y.T. Zhu ${ }^{\text {a, b, * }}$ X.L. Wu ${ }^{\text {c, d, ** }}$ \\ a Nano and Heterostructural Materials Center, Nanjing University of Science and Technology, 200 Xiaolingwei Road, Nanjing 210094, China \\ ${ }^{\mathrm{b}}$ Department of Materials Science and Engineering, North Carolina State University, 1001 Capability Drive, Raleigh, NC 27695, USA \\ ' State Key Laboratory of Nonlinear Mechanics, Institute of Mechanics, Chinese Academy of Sciences, 15 Beisihuan West Road, Beijing 100190, China \\ d College of Engineering Sciences, University of Chinese Academy of Sciences, 19A Yuquan Road, Beijing 100049, China
}

\section{A R T I C L E I N F O}

\section{Article history:}

Available online 14 September 2018

\section{Keywords:}

Ductility

Plasticity

Nanostructure

Metal

\begin{abstract}
A B S T R A C T
Ductility is one of the most important mechanical properties for metallic structural materials. It is measured as the elongation to failure of a sample during standard uniaxial tensile tests. This is problematic and often leads to gross overestimation for nanostructured metals, for which non-standard small samples are typically used. Uniform elongation is a better measure of ductility for small samples because they are less sensitive to sample size. By definition, ductility can be considered as tensile plasticity, but it is often confused with plasticity. In principle, ductility is largely governed by strain hardening rate, which is in turn significantly affected by microstructure, whereas plasticity is primarily controlled by crystal structure or the number of available slip systems to accommodate plastic deformation. In practice, ductility is important for preventing catastrophic failure of structural components during service, whereas plasticity is critical for shaping and forming metals into desired shape and geometry to make structural components. Nanostructured metals typically have high plasticity, but low ductility, due to their low strain hardening capability. Increasing strain hardening rate via modifying microstructure is the primary route to improving ductility.
\end{abstract}

() 2018 Published by Elsevier Ltd.

\section{Introduction}

Reasonable ductility (usually $>5 \%$, preferably $>10 \%$ ) is desired to prevent mechanical components or structures from catastrophic failure during service [1]. On the other hand, high strength is also desired so that a metallic structure/component can carry large load at low material weight. This is especially important for future transportation vehicles such as electrical cars, which need to be lightweight to improve their energy efficiency. However, a metallic material is either strong or ductile, but rarely both at the same time $[2,3]$. Coarse-grained (CG) metals usually have high ductility but low strength. Refining grains to the nanocrystalline regime in the last few decades has significantly increased strength, but this is often accompanied with the sacrifice of ductility [4]. The low ductility of nanostructured metals has been a major issue with their potential structural applications.

\footnotetext{
* Corresponding author.

** Corresponding author.

E-mail addresses: ytzhu@ncsu.edu (Y.T. Zhu), xlwu@imech.ac.cn (X.L. Wu).
}

Ductility of nanostructured metals has been a hot research topic for over a decade [2-7]. However, despite the extensive research and publications, there still exist widespread confusions and misconceptions on the definition and measurement of ductility of nanostructured metals, which have led to the publications of problematic claims and data.

The biggest confusion is on the difference between ductility and plasticity. Plasticity is an important property for metallic materials, which could significantly affect their processing, shaping, and forming ability. Unfortunately, in the academic literature, these two terminologies are often mixed up and interchanged, which has raised serious issues and sometimes led to wrong and/or misleading scientific claims and statements. What is more problematic is that such publications often mislead the research community, especially junior researchers and students, as well as the public. To make things worse, plasticity and ductility are often not well defined in textbooks, e.g. Deformation and Fracture Mechanics of Engineering Materials [8]. These problems become more serious in recent years with the study of nanostructured metals, in which very small, non-standard samples are often used to characterize mechanical properties. 
In this article, we will first discuss the differences between ductility and plasticity, clarify some common misconceptions and confusions, and then briefly discuss recent progresses in improving the ductility of nanostructured metals.

\section{Ductility}

In the Wikipedia [https://en.wikipedia.org/wiki/Ductility], ductility is defined as 'a solid materials' ability to deform under tensile stress.' Quantitatively, ductility is usually measured as the elongation to failure, i.e. the total engineering strain at failure, from the tensile testing of standard large samples. Fig. 1 schematically shows a typical tensile specimen before and during strain localization (necking) during a tensile test, and Fig. 2 shows the corresponding engineering stress-strain curve. The total engineering strain at failure is defined as

$\varepsilon=\frac{\Delta l}{l_{0}}=\frac{\Delta l_{u}}{l_{0}}+\frac{\Delta l_{n}}{l_{0}}=\varepsilon_{u}+\varepsilon_{n}$

where $l_{0}$ is the initial gage length, $\Delta l$ is the total gage length change after the tensile test, $\Delta l_{u}$ is the uniform gage length change during the tensile test, $\Delta l_{n}$ is the local length change in the necking segment, $\varepsilon_{u}$ is the uniform elongation, and $\varepsilon_{n}$ is the necking strain.

As shown in Fig. 2, the uniform elongation is determined by the maximum stress in the engineering stress-strain curve. In the true stress-strain curve obtained under a constant strain rate, it is often determined by the Considère criterion [4]:

$\frac{d \sigma_{t}}{d \varepsilon_{t}} \geq \sigma_{t}$

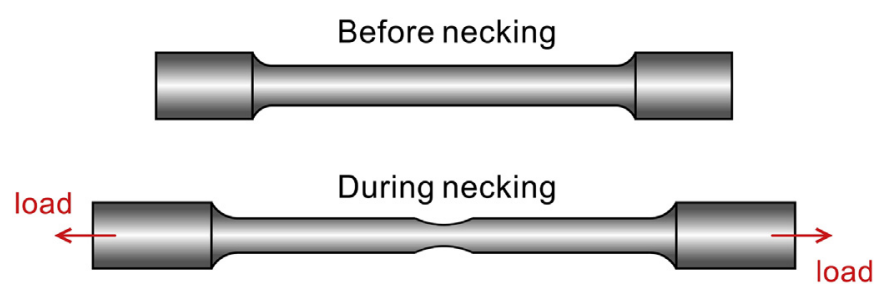

Fig. 1. Schematic illustration of sample geometry change before and during necking during a tensile test.

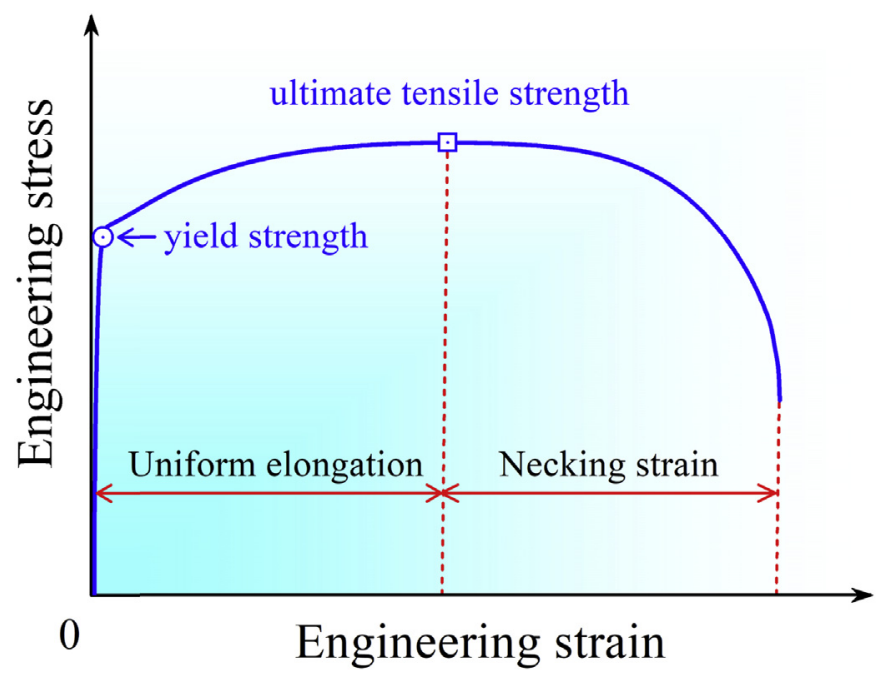

Fig. 2. Typical tensile engineering stress-strain curve. where $\sigma_{t}$ is the true stress and $\varepsilon_{t}$ is the true strain. Note that the Considère criterion can be derived to agree with maximum stress criterion for the engineering stress-strain curve, i.e.

$\frac{d \sigma_{e}}{d \varepsilon_{e}} \geq 0$

where $\sigma_{e}$ is the engineering stress and $\varepsilon_{e}$ is the engineering strain. In other words, the strain hardening rate largely determines the uniform deformation, which can be measured as the engineering strain at maximum engineering stress.

It should be noted that the Considère criterion does not consider the influence of strain rate sensitivity, which could also affect the ductility, especially at relatively high homologous temperatures and/or very small grain sizes in which the strain rate sensitivity is relatively high [5]. Hart's criterion [9] can take into account both the strain hardening and strain rate sensitivity:

$\left(\frac{d \sigma_{t}}{d \varepsilon_{t}}\right) \frac{1}{\sigma_{t}}+m \geq 1$

where $m$ is the strain rate sensitivity.

For most nanostructured metals and alloys, the strain rate sensitivity $m$ is very small ( $\ll 0.1$ ), and therefore can be ignored, in which case the Considère criterion is applicable. There are also cases in which $m$ is relatively large at room temperature for nanostructured metals with low melting temperatures [5,10,11].

Application of the Hart's criterion is not easy because the strain rate sensitivity is usually not readily available. It is clear that the uniform deformation determined by the Hart's criterion (Eq. (4)) will be higher than what is determined by the Considère criterion (Eq. (2)) if the strain rate sensitivity is not negligible. In other words, the strain hardening required to maintain uniform elongation is smaller in the Hart's criterion than in the Considère criterion.

To increase the ductility of a metal, one should try to postpone unstable necking by increasing the uniform elongation. The Considère criterion tells us that we need to increase the strain hardening rate to delay localized deformation (necking). Hart's criterion implies that although increasing strain hardening is the primary way to increase ductility, enhancing the strain rate sensitivity also helps by some limited extents for most nanostructured metals.

Ductility is an important property for a metal to undergo tensile forming such as wire drawing or to serve under tensile load, such as rebars in a bridge beam. Without sufficient ductility, a structure or machine part serving under tensile load may fail catastrophically.

\section{Plasticity}

Plasticity is the ability of a solid material to undergo plastic deformation without fracture. The plasticity of a metal is mostly determined by its intrinsic crystal structure and available slip systems. According to von Mises's rule [12], five independent slip systems are required to plastically deform a metal without forming discontinuity (crack). Face-centered cubic (fcc) metals have 12 independent slip systems, whereas body-centered cubic (bcc) metals have 48 independent slip systems. Therefore, fcc and bcc metals usually have high plasticity and can be easily shaped and formed by rolling, forging, extrusion, etc. In comparison, hexagonal close packed (hcp) metals have less than five slip system and usually need deformation twinning to meet the von Mises's requirement, which is why deformation twinning is always activated during their deformation beyond a certain plastic strain. As a result, hcp metals have much lower plasticity than fcc and bcc metals. For example, hcp Ti cannot be deformed by equal channel angular pressing using 
a $90^{\circ}$ die at room temperature due to its low plasticity [9]. For the same reason, hcp Mg has low plasticity during cold rolling [13].

Plasticity can also be affected by microstructures and defect densities. For example, a metal workpiece that is cold rolled to a high strain could have high density of entangled immobile dislocations, which may reduce its plasticity to such an extent that further cold rolling becomes impossible. Annealing the cold-rolled workpiece to induce recrystallization is a common practice to remove dislocations and to recover its plasticity. Because plastic deformation is realized by the slip of dislocations, it is easy to understand that plasticity will be reduced if dislocations are pinned by solute atoms, especially interstitial atoms such as $\mathrm{C}$ and $\mathrm{N}$. This may lead to the well-known 'ductile-to-brittle' transition in steels below a critical temperature [14]. This is especially severe for bcc steels, in which screw dislocations need thermal activation to slip, which controls the deforamtion behavior.

Plasticity is an important property for the shaping and forming of metals such as rolling, forging, extrusion, etc. Plasticity can be usually measured under compressive stress because mechanical stability (necking) normally does not occur under such a loading condition. In cases in which local shear band-induced instability occurs during compressive testing, other deformation modes such as rolling could be used to evaluate the plasticity. It should be noted that the plasticity observed under different deformation modes is different. However, a brittle material will be brittle under any deformation mode, and a metal with good plasticity should be able to be deformed to large plastic strains under several, if not all, deformation modes.

\section{Relationship between ductility and plasticity}

Ductility can be considered as a special case of plasticity: i.e. plasticity under tensile loading. High plasticity is a prerequisite for high ductility but does not guarantee high ductility. This is the case for most nanostructured metals and alloys, which usually have low ductility although they have high plasticity. This is because nanostructured metals have low to zero strain hardening. Ductility is significantly affected by a microstructure. A microstructure that provides for more locations for dislocation accumulation will lead to higher ductility.

In contrast, plasticity is primarily determined by the mobility of dislocations and available slip systems. If there are not enough slip systems to meet the von Mises's rule [12], plasticity is largely determined by the activation of other deformation modes such as twinning, grain boundary sliding, grain rotation, etc.

\section{Confusions, misconceptions, and clarifications}

There has been considerable confusion about ductility and plasticity in our community. These two terminologies are often mixed and interchanged in a large number of peer-reviewed academic articles and conference presentations. Therefore, there is an urgent need to clarify these confusions and misconceptions. We will list the most common misconceptions/confusions in the following and clarify them.

\subsection{Misconception/confusion 1: tensile ductility}

The terminology 'tensile ductility' is often used in the literature. From the first look, there is nothing wrong with it because ductility is indeed measured from tensile testing. However, this terminology hints at the existence of other types of ductility. Indeed, there are articles that reported ductility measurement under compressive stress, which is conceptually wrong. Therefore, one can say ductility or tensile plasticity, but not tensile ductility.

\subsection{Misconception/confusion 2: mobile dislocations lead to good ductility}

If high density of mobile dislocations is observed by transmission electron microscopy and/or other characterization techniques, it only means that the material has good plasticity but does not necessarily have good ductility. However, if dislocations are observed to effectively accumulate at many microstructural features such as twins and second-phase particles, good ductility can be expected because dislocation accumulation produces work hardening, which promotes ductility [15-17]. In other words, dislocation gliding produces plasticity while blocking gliding dislocations to force them to accumulate produces ductility.

\subsection{Misconception/confusion 3: low ductility equals low plasticity}

Low plasticity will certainly lead to low ductility, but the reverse may not be true. A material with no plasticity is considered brittle, such as glass and most ceramic materials, which will shatter when deformed under common deformation modes such as tension, compression, bending, etc. at room temperature. Brittle materials typically have no mobile dislocations available to accommodate plastic deformation when deformed. The fracture surfaces of brittle materials often exhibit intragrain cleavage or grain boundary failure.

Materials with plasticity deform normally by dislocation slip, and their fracture surfaces exhibit dimples that are generated by dislocation activities at the final fracture stage. Such a fracture is called 'ductile fracture' in the textbooks, which is partially responsible for the confusion and mix-up between ductility and plasticity. This problem is not serious for conventional CG metals because CG metals with ductile fracture typically have good ductility. However, this posts a big problem for nanostructured metals, which typically exhibit dimples on their fracture surface [18], but still have poor ductility. In other words, dimples on the fracture surface are associated with plasticity, but not necessarily with ductility.

\subsection{Misconception/confusion 4: cross-area reduction as an indicator of ductility}

There have been suggestions to use the cross-area reduction at fracture as a measure/indicator of ductility for nanostructured metals. This is reasonable for conventional CG metals because these two material properties are often well correlated. However, for nanostructured metals, they are disconnected. Nanostructured metals usually have large cross-area reduction although they have low ductility. Therefore, the cross-area reduction is correlated with plasticity, but not ductility, just like the dimples at the fracture surface.

Nanostructured metals typically have dimpled fracture surface, large cross-area reduction, and high plasticity, but poor ductility. They are not brittle because they can be deformed plastically.

\section{Issues for nanostructured materials}

\subsection{Sample size effect}

Most research groups have been using small, non-standard samples to measure the mechanical properties, and some groups even used non-tensile loading such as compression of micro-sized pillars to measure ductility. The small samples are due to the difficulty in making nanostructured materials large enough for standard mechanical testing. 
It has been found that the sample size and geometry have significant effect on the stress-strain curves and hence the measured ductility $[19,20]$. For example, the gage length effect can be demonstrated using Eq. (1). The $\Delta l_{u}$, which is the uniform gage length change during the tensile test, should be proportional to the original gage length $l_{0}$. Therefore, the uniform elongation should not be affected by the gage length of the sample if the sample gage length is not so short that it induces a three-dimensional stress state [20]. On the other hand, the $\Delta l_{n}$ is the local necking length and is independent of the initial gage length $l_{0}$. Therefore, the necking strain $\varepsilon_{\mathrm{n}}=\Delta l_{n} / l_{0}$ will increase dramatically with decreasing gage length $l_{0}$, especially when the gage length is small. This often leads to a situation in which the necking strain is much larger than the uniform strain, and the elongation to failure becomes largely decided by the gage length. Therefore, ductility, if defined as the elongation to failure, often becomes artificially high and meaningless. This also makes the ductility data from different groups not comparable. Unfortunately, most ductility data of nanostructured metals in the literature are measured as the elongation to failure, which are problematic and have to be taken with a grain of salt.

To alleviate this problem, it is advised to use the uniform elongation as a measure of ductility, which is not affected by the gage length, unless the gage length is approaching the necking length, which causes three-dimensional stresses [20]. In addition, the sample size effect might be reduced if the geometry of small tensile samples is proportional to that of the standard sample, but this needs further investigation. If it is not possible to maintain a proportional geometry, it is advised to at least make the gage length relatively long.

\subsection{Approaches to improve ductility}

After understanding the definition of ductility and what factors affect it the most, we can develop approaches to improve ductility. As shown in Eqs. (2)-(4), to improve the ductility of nanostructured metals, the most effective approach is to increase their strain hardening rate. In other words, we need to design nanostructures that can effectively block and accumulate dislocations. It should be noted that nanostructured metals have high flow stress, which makes it necessary for them to have much higher strain hardening than their CG counterparts to retain the same ductility, as shown in the Considère criterion.

In nanostructured metals, grain boundaries are no longer effective for dislocation accumulation. This is because the grain sizes are so small that dislocation sources no longer exist in the grain interior, and grain boundaries become dislocation source and sink without much dislocation accumulation [21]. It follows that we should make dislocation barriers inside the grain interior to block and accumulate dislocations. Many strategies have been proposed to enhance the ductility of nanostructured metals, including preexisting and deformation twins [15,21-49], second-phase precipitates [16,50-62], hetero-phase interfaces/grain boundaries [63-65], stacking faults [66-68], and high-angle grain boundaries $[17,69,70]$. Because these approaches can also increase the strength, they often lead to simultaneous increase in both yield strength and ductility.

It should be also noted that ultrafine grained metals processed by severe plastic deformation techniques often contain high density of dislocations. This leaves little room for dislocation accumulation during tensile test before dislocation saturation is reached. Therefore, annealing to lower the dislocation density without increasing the grain size is expected to improve strain hardening and ductility.

Strain rate sensitivity may also play a significant role in increasing ductility for some metals with low melting temperature.
In such cases, room temperature represents a relatively high homologous temperature $\left(\mathrm{T} / \mathrm{T}_{\mathrm{m}}\right)$, which when coupled with fine grain sizes could produce a relatively high strain rate sensitivity to make the nanostructured metal deform in a quasi-superplastic behavior [10]. Indeed, for nanostructured metals and alloys with low melting temperatures such as $\mathrm{Al}$ and $\mathrm{Zn}$, grain boundary sliding was observed at room temperature, which is a deformation mechanism with high strain rate sensitivity [11,71].

For nanostructured fcc metals, decreasing the grain size normally leads to the increase in strain rate sensitivity. For nanostructured bcc metals, the strain rate sensitivity has been observed to decrease with decreasing grain size [72,73]. These changes of strain rate sensitivity with grain size are relatively small when compared with the change in strain hardening rate. The strain hardening rate of nanostructured metals is dramatically decreased and often becomes close to zero [3-5,74], which is why nanostructured metals and alloys usually have very poor ductility. Therefore, enhancing the strain hardening rate is the primary route to improving the ductility of nanostructured metals [3-5].

Recently, it is found that heterostructures can also help with improving the ductility $[12,75-80]$. Heterostructures produce significant back stress-induced work hardening, in addition to the conventional dislocation hardening as expressed by the Ashby equation [81,82]:

$\tau=\alpha G b \sqrt{\rho_{S}+\rho_{G}}$

where $\alpha$ is a constant, $G$ is the shear modulus, $b$ is the magnitude of Burgers vector, $\rho_{S}$ is the density of statistically stored dislocations, and $\rho_{G}$ is the density of geometrically necessary dislocations (GNDs). In heterostructured metals, the GNDs produce significant synergistic long-range back stress to enhance the yield strength as well as the high back stress hardening to enhance/retain ductility.

\section{Summary}

Ductility and plasticity are two related but different concepts. High plasticity is a perquisite for high ductility but does not guarantee high ductility. Ductility can be regarded as tensile plasticity and can only be measured using tensile tests. When small samples are used, uniform elongation is a better way to measure ductility than elongation to failure because uniform elongation is much less affected by the sample size.

Nanostructured metals typically have high plasticity but low ductility. The primary approach to improve their ductility is to improve strain hardening rate by engineering nanostructure. Strain hardening can be enhanced by the accumulation of crystalline defects such as dislocations and twins as well as by back stress-induced strain hardening. For metals with relatively low melting temperature, strain rate sensitivity could play a notable role in improving ductility.

\section{Competing financial interests}

The authors declare no competing financial interests.

\section{Acknowledgments}

This work was supported by the National Key R\&D Program of China (Grant Nos. 2017YFA0204402 and 2017YFA0204403). X.W. was also funded by the Natural Science Foundation of China (Grant Nos. 11572328, 11672313, and 11790293), the Strategic Priority Research Program of the Chinese Academy of Sciences (Grant No. XDB22040503). 


\section{References}

[1] Properties and selection: nonferrous alloys and special-purpose materials, in: J.R. Davis (Ed.), ASM International Handbook Committee, Metals Handbook, vol. 2, ASM International, Materials Park, Ohio, 2000.

[2] R.Z. Valiev, I.V. Alexandrov, Y.T. Zhu, T.C. Lowe, Paradox of strength and ductility in metals processed by severe plastic deformation, J. Mater. Res. 17 (2002) 5-8.

[3] Y.T. Zhu, X.Z. Liao, Nanostructured metals: retaining ductility, Nat. Mater. 3 (2004) 351-352.

[4] R.Z. Valiev, Y. Estrin, Z. Horita, T.G. Langdon, M.J. Zehetbauer, Y.T. Zhu, Fundamentals of superior properties in bulk nanospd materials, Mater. Res. Lett. 4 (2016) $1-21$.

[5] I.A. Ovid'ko, R.Z. Valiev, Y.T. Zhu, Review on superior strength and enhanced ductility of metallic nanomaterials, Prog. Mater. Sci. 94 (2018) 462-540.

[6] Y.M. Wang, E. Ma, Three strategies to achieve uniform tensile deformation in a nanostructured metal, Acta Mater. 52 (2004) 1699-1709.

[7] T.H. Fang, W.L. Li, N.R. Tao, K. Lu, Revealing extraordinary intrinsic tensile plasticity in gradient nano-grained copper, Science 331 (2011) 1587-1590.

[8] R.W. Hertzberg, Deformation and Fracture Mechanics of Engineering Materials, Wiley, New York, 1989.

[9] D.P. DeLo, S.L. Semiatin, Hot working of Ti-6Al-4V via equal channel angular extrusion, Metall. Trans. A 30 (1999) 2473-2481.

[10] R.Z. Valiev, M.Y. Murashkin, A. Kilmametov, B. Straumal, N.Q. Chinh, T.G. Langdon, Unusual super-ductility at room temperature in an ultrafinegrained aluminum alloy, J. Mater. Sci. 45 (2010) 4718-4724.

[11] X. Zhang, H. Wang, R.O. Scattergood, J. Narayan, C.C. Koch, A.V. Sergueeva, A.K. Mukherjee, Tensile elongation (110\%) observed in ultrafine-grained $\mathrm{Zn}$ at room temperature, Appl. Phys. Lett. 81 (2002) 823-825.

[12] X.L. Wu, P. Jiang, L. Chen, F.P. Yuan, Y.T. Zhu, Extraordinary strain hardening by gradient structure, Proc. Natl. Acad. Sci. U. S. A. 111 (2014) 7197-7201.

[13] M.R. Barnett, N. Stanford, P. Cizek, A. Beer, Z. Xuebin, Z. Keshavarz, Deformation mechanisms in $\mathrm{Mg}$ alloys and the challenge of extending roomtemperature plasticity, JOM 61 (2009) 19-24.

[14] R.W. Cahn, Physical Metallurgy, North-Holland Publishing Company, Amsterdam, 1977.

[15] K. Lu, L. Lu, S. Suresh, Strengthening materials by engineering coherent internal boundaries at the nanoscale, Science 324 (2009) 349-352.

[16] Y.H. Zhao, X.Z. Liao, S. Cheng, E. Ma, Y.T. Zhu, Simultaneously increasing the ductility and strength of nanostructured alloys, Adv. Mater. 18 (2006) 2280-2283.

[17] Y.H. Zhao, Y.T. Zhu, E.J. Lavernia, Strategies for improving tensile ductility of bulk nanostructured materials, Adv. Eng. Mater. 12 (2010) 769-778.

[18] Y.T. Zhu, J.Y. Huang, J. Gubicza, T. Ungar, Y.M. Wang, E. Ma, R.Z. Valiev, Nanostructures in Ti processed by severe plastic deformation, J. Mater. Res. 18 (2003) 1908-1917.

[19] Y.H. Zhao, Y.Z. Guo, Q. Wei, A.M. Dangelewiez, Y.T. Zhu, T.G. Langdon, Y.Z. Zhou, E.J. Lavernia, C. Xu, Influence of specimen dimensions on the tensile behavior of ultrafine-grained Cu, Scr. Mater. 59 (2008) 627-630.

[20] Y.H. Zhao, Y.Z. Guo, Q. Wei, T.D. Topping, A.M. Dangelewicz, Y.T. Zhu, T.G. Langdon, E.J. Lavernia, Influence of specimen dimensions and strain measurement methods on tensile stress-strain curves, Mater. Sci. Eng. A 525 (2009) 68-77.

[21] Y.T. Zhu, X.Z. Liao, X.L. Wu, Deformation twinning in nanocrystalline materials, Prog. Mater. Sci. 57 (2012) 1-62.

[22] J.W. Christian, S. Mahajan, Deformation twinning, Prog. Mater. Sci. 39 (1995) $1-157$.

[23] O. Anderoglu, A. Misra, J. Wang, R.G. Hoagland, J.P. Hirth, X. Zhang, Plastic flow stability of nanotwinned Cu foils, Int. J. Plast. 26 (2010) 875-886.

[24] C.H. Caceres, P. Lukac, A. Blake, Strain hardening due to $\{10-12\}$ twinning in pure magnesium, Philos. Mag. 88 (2008) 991-1003.

[25] L. Capolungo, I.J. Beyerlein, Nucleation and stability of twins in HCP metals, Phys. Rev. B 78 (2008) 024117.

[26] A.Y. Chen, J.B. Liu, H.T. Wang, J. Lu, Y.M. Wang, Gradient twinned 304 stainless steels for high strength and high ductility, Mater. Sci. Eng. A 667 (2016) 179-188.

[27] M. Dao, L. Lu, Y.F. Shen, S. Suresh, Strength, strain-rate sensitivity and ductility of copper with nanoscale twins, Acta Mater. 54 (2006) 5421-5432.

[28] M.J. Demkowicz, O. Anderoglu, X.H. Zhang, A. Misra, The influence of $\Sigma 3$ twin boundaries on the formation of radiation-induced defect clusters in nanotwinned Cu, J. Mater. Res. 26 (2011) 1666-1675.

[29] S. Kibey, J.B. Liu, D.D. Johnson, H. Sehitoglu, Generalized planar fault energies and twinning in Cu-Al alloys, Appl. Phys. Lett. 89 (2006) 191911.

[30] S. Kibey, J.B. Liu, D.D. Johnson, H. Sehitoglu, Predicting twinning stress in FCC metals: linking twin-energy pathways to twin nucleation, Acta Mater. 55 (2007) 6843-6851.

[31] S.A. Kibey, L.L. Wang, J.B. Liu, H.T. Johnson, H. Sehitoglu, D.D. Johnson, Quantitative prediction of twinning stress in fcc alloys: application to $\mathrm{Cu}-\mathrm{Al}$ Phys. Rev. B 79 (2009) 214202.

[32] X.Y. Li, Y.J. Wei, L. Lu, K. Lu, H.J. Gao, Dislocation nucleation governed softening and maximum strength in nano-twinned metals, Nature 464 (2010) 877-880.

[33] L. Lu, R. Schwaiger, Z.W. Shan, M. Dao, K. Lu, S. Suresh, Nano-sized twins induce high rate sensitivity of flow stress in pure copper, Acta Mater. 53 (2005) 2169-2179.
[34] M.A. Meyers, O. Vohringer, V.A. Lubarda, The onset of twinning in metals: a constitutive description, Acta Mater. 49 (2001) 4025-4039.

[35] A. Ojha, H. Sehitoglu, L. Patriarca, H.J. Maier, Twin nucleation in Fe-based bcc alloys-modeling and experiments, Model. Simul. Mater Sci. Eng. 22 (2014) 075010.

[36] A. Ojha, H. Sehitoglu, L. Patriarca, H.J. Maier, Twin migration in Fe-based bcc crystals: theory and experiments, Philos. Mag. 94 (2014) 1816-1840.

[37] Y.F. Shen, L. Lu, M. Dao, S. Suresh, Strain rate sensitivity of Cu with nanoscale twins, Scr. Mater. 55 (2006) 319-322.

[38] Y.F. Shen, L. Lu, Q.H. Lu, Z.H. Jin, K. Lu, Tensile properties of copper with nanoscale twins, Scr. Mater. 52 (2005) 989-994.

[39] J. Wang, O. Anderoglu, J.P. Hirth, A. Misra, X. Zhang, Dislocation structures of $\Sigma 3\{112\}$ twin boundaries in face centered cubic metals, Appl. Phys. Lett. 95 (2009) 021908

[40] J. Wang, N. Li, O. Anderoglu, X. Zhang, A. Misra, J.Y. Huang, J.P. Hirth, Detwinning mechanisms for growth twins in face-centered cubic metals, Acta Mater. 58 (2010) 2262-2270.

[41] F.K. Yan, G.Z. Liu, N.R. Tao, K. Lu, Strength and ductility of 316L austenitic stainless steel strengthened by nano-scale twin bundles, Acta Mater. 60 (2012) 1059-1071.

[42] L. Lu, Y.F. Shen, X.H. Chen, L.H. Qian, K. Lu, Ultrahigh strength and high electrical conductivity in copper, Science 304 (2004) 422-426.

[43] X.Z. Liao, Y.H. Zhao, S.G. Srinivasan, Y.T. Zhu, R.Z. Valiev, D.V. Gunderov, Deformation twinning in nanocrystalline copper at room temperature and low strain rate, Appl. Phys. Lett. 84 (2004) 592-594.

[44] X.Z. Liao, F. Zhou, E.J. Lavernia, S.G. Srinivasan, M.I. Baskes, D.W. He, Y.T. Zhu, Deformation mechanism in nanocrystalline Al: partial dislocation slip, Appl. Phys. Lett. 83 (2003) 632-634.

[45] X.L. Ma, W.Z. Xu, H. Zhou, J.A. Moering, J. Narayan, Y.T. Zhu, Alloying effect on grain-size dependent deformation twinning in nanocrystalline $\mathrm{Cu}-\mathrm{Zn}$ alloys, Philos. Mag. 95 (2015) 301-310.

[46] X.L. Wu, X.Z. Liao, S.G. Srinivasan, F. Zhou, E.J. Lavernia, R.Z. Valiev, Y.T. Zhu, New deformation twinning mechanism generates zero macroscopic strain in nanocrystalline metals, Phys. Rev. Lett. 100 (2008) 095701.

[47] X.L. Wu, Y.T. Zhu, Inverse grain-size effect on twinning in nanocrystalline Ni, Phys. Rev. Lett. 101 (2008) 025503.

[48] Y.T. Zhu, X.Z. Liao, X.L. Wu, J. Narayan, Grain size effect on deformation twinning and detwinning, J. Mater. Sci. 48 (2013) 4467-4475.

[49] W.W. Jian, G.M. Cheng, W.Z. Xu, C.C. Koch, Q.D. Wang, Y.T. Zhu, S.N. Mathaudhu, Physics and model of strengthening by parallel stacking faults, Appl. Phys. Lett. 103 (2013) 133108.

[50] Y.N. Osetsky, D.J. Bacon, V. Mohles, Atomic modelling of strengthening mechanisms due to voids and copper precipitates in alpha-iron, Philos. Mag. 83 (2003) 3623-3641.

[51] C. Xu, M. Furukawa, Z. Horita, T.G. Langdon, Influence of ECAP on precipitate distributions in a spray-east aluminum alloy, Acta Mater. 53 (2005) $749-758$.

[52] S. Cheng, Y.H. Zhao, Y.T. Zhu, E. Ma, Optimizing the strength and ductility of fine structured $2024 \mathrm{Al}$ alloy by nano-precipitation, Acta Mater. 55 (2007) $5822-5832$.

[53] D. Raabe, D. Ponge, O. Dmitrieva, B. Sander, Nanoprecipitate-hardened 1.5 GPa steels with unexpected high ductility, Scr. Mater. 60 (2009) 1141-1144.

[54] G. Sha, Y.B. Wang, X.Z. Liao, Z.C. Duan, S.P. Ringer, T.G. Langdon, Influence of equal-channel angular pressing on precipitation in an Al-Zn-Mg-Cu alloy, Acta Mater. 57 (2009) 3123-3132.

[55] J. Geng, Y.B. Chun, N. Stanford, C.H.J. Davies, J.F. Nie, M.R. Barnett, Processing and properties of Mg-6Gd-1Zn-0.6Zr Part 2. Mechanical properties and particle twin interactions, Mater. Sci. Eng. A 528 (2011) 3659-3665.

[56] B.L. Zheng, O. Ertorer, Y. Li, Y.Z. Zhou, S.N. Mathaudhu, C.Y.A. Tsao, E.J. Lavernia, High strength, nano-structured Mg-Al-Zn alloy, Mater. Sci. Eng. A 528 (2011) 2180-2191.

[57] J.F. Nie, Precipitation and hardening in magnesium alloys, Metall. Mater. Trans. A 43 (2012) 3891-3939.

[58] M.H. Tsai, H. Yuan, G.M. Cheng, W.Z. Xu, W.W. Jian, M.H. Chuang, C.C. Juan, A.C. Yeh, S.J. Lin, Y.T. Zhu, Significant hardening due to the formation of a sigma phase matrix in a high entropy alloy, Intermetallics 33 (2013) 81-86.

[59] K. Li, A. Beche, M. Song, G. Sha, X.X. Lu, K. Zhang, Y. Du, S.P. Ringe, D. Schryvers, Atomistic structure of $\mathrm{Cu}$-containing $\beta^{\prime \prime}$ precipitates in an Al-MgSi-Cu alloy, Scr. Mater. 75 (2014) 86-89.

[60] Y.H. Zhao, X.Z. Liao, Z. Jin, R.Z. Valiev, Y.T. Zhu, Microstructures and mechanical properties of ultrafine grained $7075 \mathrm{Al}$ alloy processed by ECAP and their evolutions during annealing, Acta Mater. 52 (2004) 4589-4599.

[61] P.V. Liddicoat, X.Z. Liao, Y.H. Zhao, Y.T. Zhu, M.Y. Murashkin, E.J. Lavernia, R.Z. Valiev, S.P. Ringer, Nanostructural hierarchy increases the strength of aluminum alloys, Nat. Commun. 1 (2010) 63.

[62] X.L. Wu, F.P. Yuan, M.X. Yang, P. Jiang, C.X. Zhang, L. Chen, Y.G. Wei, E. Ma, Nanodomained nickel unite nanocrystal strength with coarse-grain ductility, Sci. Rep. 5 (2015) 11728.

[63] M.X. Yang, F.P. Yuan, Q.G. Xie, Y.D. Wang, E. Ma, X.L. Wu, Strain hardening in Fe-16Mn-10Al-0.86C-5Ni high specific strength steel, Acta Mater. 109 (2016) $213-222$.

[64] Y. Ma, F.P. Yuan, M.X. Yang, P. Jiang, E. Ma, X.L. Wu, Dynamic shear deformation of a $\mathrm{CrCoNi}$ medium-entropy alloy with heterogeneous grain structures, Acta Mater. 148 (2018) 407-418. 
[65] M.X. Yang, D.S. Yan, F.P. Yuan, P. Jiang, E. Ma, X.L. Wu, Dynamically reinforced heterogeneous grain structure prolongs ductility in a medium-entropy alloy with gigapascal yield strength, Proc. Natl. Acad. Sci. U. S. A. 115 (2018) 7224-7229.

[66] A.A. Karimpoor, U. Erb, K.T. Aust, G. Palumbo, High strength nanocrystalline cobalt with high tensile ductility, Scr. Mater. 49 (2003) 651-656.

[67] W.W. Jian, G.M. Cheng, W.Z. Xu, H. Yuan, M.H. Tsai, Q.D. Wang, C.C. Koch, Y.T. Zhu, S.N. Mathaudhu, Ultrastrong Mg alloy via nano-spaced stacking faults, Mater. Res. Lett. 1 (2013) 61-66.

[68] Y.H. Zhao, Y.T. Zhu, X.Z. Liao, Z. Horita, T.G. Langdon, Tailoring stacking fault energy for high ductility and high strength in ultrafine grained $\mathrm{Cu}$ and its alloy, Appl. Phys. Lett. 89 (2006) 121906.

[69] Y.H. Zhao, J.F. Bingert, Y.T. Zhu, X.Z. Liao, R.Z. Valiev, Z. Horita, T.G. Langdon, Y.Z. Zhou, E.J. Lavernia, Tougher ultrafine grain $\mathrm{Cu}$ via high-angle grain boundaries and low dislocation density, Appl. Phys. Lett. 92 (2008) 081903.

[70] C.X. Huang, W.P. Hu, Q.Y. Wang, C. Wabg, G. Yang, Y.T. Zhu, An ideal ultrafinegrained structure for high strength and high ductility, Mater. Res. Lett. 3 (2015) 88-94.

[71] T. Mungole, P. Kumar, M. Kawasaki, T.G. Langdon, The contribution of grain boundary sliding in tensile deformation of an ultrafine-grained aluminum alloy having high strength and high ductility, J. Mater. Sci. 50 (2015) 3549-3561.

[72] Q. Wei, S. Cheng, K.T. Ramesh, E. Ma, Effect of nanocrystalline and ultrafine grain sizes on the strain rate sensitivity and activation volume: fcc versus bcc metals, Mater. Sci. Eng. A 381 (2004) 71-79.
[73] G.M. Cheng, W.W. Jian, W.Z. Xu, H. Yuan, P.C. Millett, Y.T. Zhu, Grain size effect on deformation mechanisms of nanocrystalline bcc Metals, Mater. Res. Lett. 1 (2013) 26-31.

[74] D. Jia, Y.M. Wang, K.T. Ramesh, E. Ma, Y.T. Zhu, R.Z. Valiev, Deformation behavior and plastic instabilities of ultrafine-grained titanium, Appl. Phys. Lett. 79 (2001) 611-613.

[75] X.L. Wu, Y.T. Zhu, Heterogeneous materials: a new class of materials with unprecedented mechanical properties, Mater. Res. Lett. 5 (2017) 527-532.

[76] X.L. Wu, M.X. Yang, F.P. Yuan, L. Chen, Y.T. Zhu, Combining gradient structure and TRIP effect to produce austenite steel with high strength and ductility, Acta Mater. 112 (2016) 337-346.

[77] X.L. Wu, M.X. Yang, F.P. Yuan, G.L. Wu, Y.J. Wei, X.X. Huang, Y.T. Zhu, Heterogeneous lamella structure unites ultrafine-grain strength with coarsegrain ductility, Proc. Natl. Acad. Sci. U. S. A. 112 (2015) 14501-14505.

[78] Y.J. Wei, Y.Q. Li, L.C. Zhu, Y. Liu, X.Q. Lei, G. Wang, Y.X. Wu, Z.L. Mi, J.B. Liu, H.T. Wang, H.J. Gao, Evading the strength- ductility trade-off dilemma in steel through gradient hierarchical nanotwins, Nat. Commun. 5 (2014) 3580.

[79] K. Lu, Making strong nanomaterials ductile with gradients, Science 345 (2014) $1455-1456$

[80] M.X. Yang, Y. Pan, F.P. Yuan, Y.T. Zhu, X.L. Wu, Back stress strengthening and strain hardening in gradient structure, Mater. Res. Lett. 4 (2016) 145-151.

[81] M.F. Ashby, Deformation of plastically non-homogeneous materials, Philos. Mag. 21 (1970) 399-424.

[82] H.J. Gao, Y.G. Huang, W.D. Nix, J.W. Hutchinson, Mechanism-based strain gradient plasticity-I. Theory, J. Mech. Phys. Solids 47 (1999) 1239-1263. 